\title{
The Effect of Bedding Structure on Mechanical Property of Coal
}

\author{
Zetian Zhang, ${ }^{1,2}$ Ru Zhang, ${ }^{1,2}$ Guo Li, ${ }^{1,2}$ Hegui Li, ${ }^{1,2}$ and Jianfeng Liu ${ }^{1,2}$ \\ ${ }^{1}$ State Key Laboratory of Hydraulics and Mountain River Engineering, Sichuan University, Chengdu 610065, China \\ ${ }^{2}$ College of Water Resource and Hydropower, Sichuan University, Chengdu 610065, China \\ Correspondence should be addressed to Ru Zhang; zhangru@scu.edu.cn
}

Received 17 March 2014; Revised 12 July 2014; Accepted 20 July 2014; Published 7 August 2014

Academic Editor: Jörg M. K. Wiezorek

Copyright (C) 2014 Zetian Zhang et al. This is an open access article distributed under the Creative Commons Attribution License, which permits unrestricted use, distribution, and reproduction in any medium, provided the original work is properly cited.

\begin{abstract}
The mechanical property of coal, influencing mining activity considerably, is significantly determined by the natural fracture distributed within coal mass. In order to study the effecting mechanism of bedding structure on mechanical property of coal, a series of uniaxial compression tests and mesoscopic tests have been conducted. The experimental results show that the distribution characteristic of calcite particles, which significantly influences the growth of cracks and the macroscopic mechanical properties of coal, is obviously affected by the bedding structure. Specifically, the uniaxial compression strength of coal sample is mainly controlled by bedding structure, and the average peak stress of specimens with axes perpendicular to the bedding planes is $20.00 \mathrm{MPa}$, which is 2.88 times the average amount of parallel ones. The test results also show a close relationship between the bedding structure and the whole deformation process under uniaxial loading.
\end{abstract}

\section{Introduction}

Due to the reduction of coal resource in surface reserves accompanied by the increasing demand of economic development for energy, the intensity of coal mining as well as its depth is continuously increasing. Accordingly, the accidents such as rock burst, coal-gas outburst, and mine water inrush are more likely to happen. At the same time, different geological structure combining with different mining methods can certainly lead to various stress concentration situations, which influences the mechanical property of coal and furthermore serves as the direct factor to induce disasters mentioned above [1]. Consequently, the relation between mechanical properties of coal and the geological structure needs to be studied thoroughly.

The strength of coal is a fundamental mechanical property for tunnel excavation and coal recovery. It also relates to the extent of disasters. As a result, numerous scholars have studied how physical and geometrical parameters affect the strength of coal, such as petrographic composition [2], size and shape of specimen [2-5], stress path [6], temperature [7], and the type of adsorptive gas and its adsorption/desorption [8-10]. In addition, the volume percentile of different chemical constituents in coal have been proved to possess distinct mechanical properties for coal sample [11] and the contribution to the strength of coal sample differs from one constituent to another. The measurements of coal strength in the laboratory also show that the strength of coal increases with the increase of confining pressure and with the decrease of pore pressure and temperature $[6,7]$. Sato et al. and Ranjith and Perera proposed that the porous structure and cleats in coal also have an effect on the strength of coal $[12,13]$. As for the geological bedding structures distributed in the sedimentary coal, $\mathrm{Li}$ and his colleagues found that the bedding structures have an impact on microseismic signals transmission in the coal [14] and Hobbs studied the primary influence of bedding structure on the strength of rectangular blocks of Barnsley hard coal crushed parallel to the bedding planes [15]. All these scholars have made significant contributions to mining engineer. However, the influence mechanism of bedding structure on coal strength has not been explored.

In this paper, an attempt is made to obtain a better understanding of the effect of bedding structure on mechanical property of coal. Based on the stress conditions of the coal pillars and the coal mass near mining face, uniaxial compression tests were conducted in the first place for two kinds of specimens whose axes are parallel or perpendicular to the bedding planes. The experimental results for the 


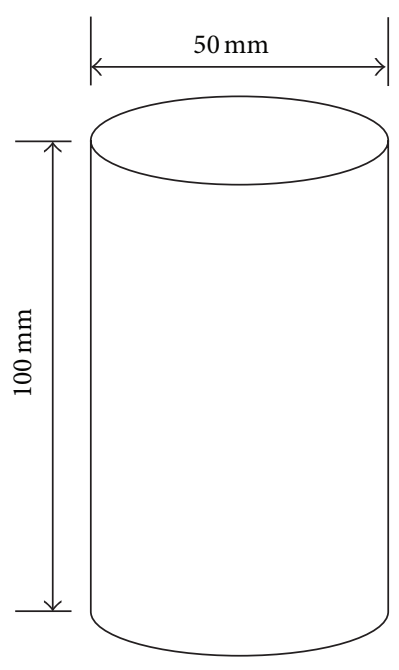

(a) Specimen size

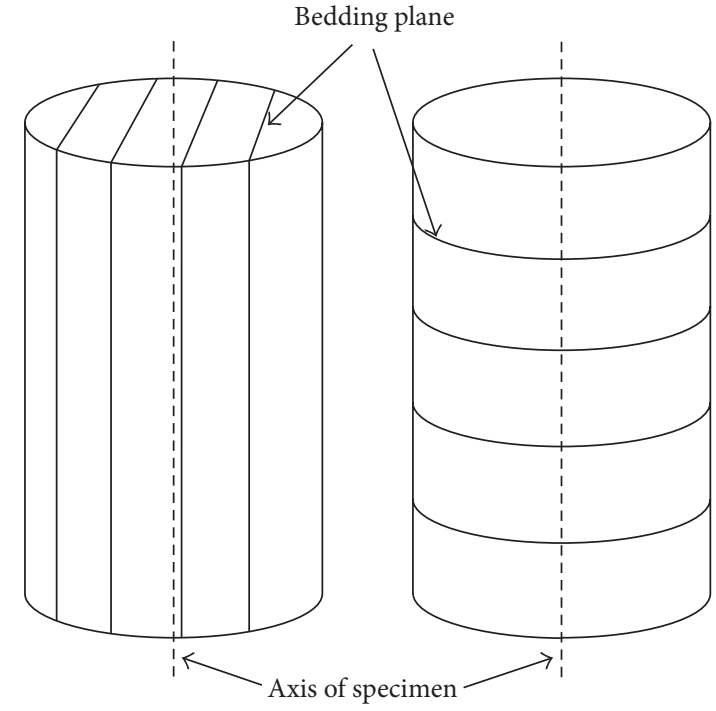

(b) Parallel specimen

(c) Perpendicular specimen

FIGURE 1: Schematic diagram of the coal specimens.

strength, deformation, and failure properties of the coal are analyzed. Combining with the mesoscopic testing results, the influence mechanism of mineral component on mechanical properties of coal is also discussed.

\section{Materials and Methods}

2.1. Specimen Preparation. The lump bituminous coal, which was drilled for coal specimens, was taken from Tashan mine of Datong coal mining group, China. The coal specimens were prepared as cylinders with dimensions of $\Phi 50 \mathrm{~mm} \times$ $H 100 \mathrm{~mm}$ according to the description in ASTM standard D4543-08. To investigate the effect of bedding structures on mechanical property of coal, the axes of coal specimens were set to be parallel or perpendicular to the bedding planes shown in Figure 1. The mineral components of specimens were mainly carbon $(71.44 \%)$, kaolinite $(20.13 \%)$, and calcite $(6.98 \%)$, and these results were obtained from X-ray diffraction meter (DMAX-3C) and X-ray fluorescence spectrometer (XRF-1800 CCED).

2.2. Apparatus. The MTS815 Flex Test GT rock mechanics testing system with high stiffness, high loading sensing accuracy $(1 \% \mathrm{kN})$, and high deformation sensing accuracy $(0.1 \% \mathrm{~mm})$ was employed to carry out the tests. Its maximum axial compression load is $4600 \mathrm{kN}$ and the testing range of axial and hoop deformation extensometer is -4.0$+4.0 \mathrm{~mm}$ and $-2.5-+12.5 \mathrm{~mm}$, respectively. Both the Industrial Computed Tomography (ICT) scanning system (ACTIS320/225X) and the Field Emission Scanning Electron Microscope (SEM) testing system (JSM-7500F) were employed to detect the internal structure of coal specimens. The spatial resolution of the ICT for the coal specimens was set as $30 \mu \mathrm{m}$, and the magnification of the SEM ranged from $\times 25$ to $\times 800,000$.
2.3. Experimental Procedures. The coal specimens were divided into two groups according to whether the drilling direction is parallel or perpendicular to the bedding planes. With each group containing five specimens, uniaxial compression tests and mesoscopic tests were conducted. The uniaxial compression tests were controlled by constant axial force loading rate $(30 \mathrm{kN} / \mathrm{min})$ at the elastic deformation stage and then by hoop deformation rate $(0.02 \mathrm{~mm} / \mathrm{min})$ just before the appearance of peak strength to get the complete stress-strain curves, which contains the postpeak section.

\section{Results and Analyses}

3.1. Mesoscopic Tests. As stated previously, the SEM and ICT have been realized for the coal samples along and perpendicular to the bedding plane shown in Figures 2 and 3, and the mineral components of these specimens are mainly carbon, kaolinite, and calcite. Due to the white color of calcite distinguished from other two minerals, it can be seen from Figures 2 and 3 that the calcite particles uniformly distribute on the bedding planes, while from the SEM and ICT images acquired on the failure surface perpendicular to the bedding planes, the calcite particles mainly concentrate along the intersection lines formed by the bedding planes and the failure surface. It can be concluded that the majority of the calcite particles distribute near or on the bedding planes.

Generally, calcite has a higher Mohs scale of hardness ranging from 2.7 to 3.0 comparing to carbon and kaolinite. This particular hardness can certainly induce inconsistence along the boundary between calcite and other mineral particles. As a result, these singularity boundaries will lead to stress concentration, crack initiation, and propagation during the deformation process. This theory can be supported from the facts shown in Figure 2, each tadpole-shaped crack begins or ends with calcite particles, and the crack patterns 


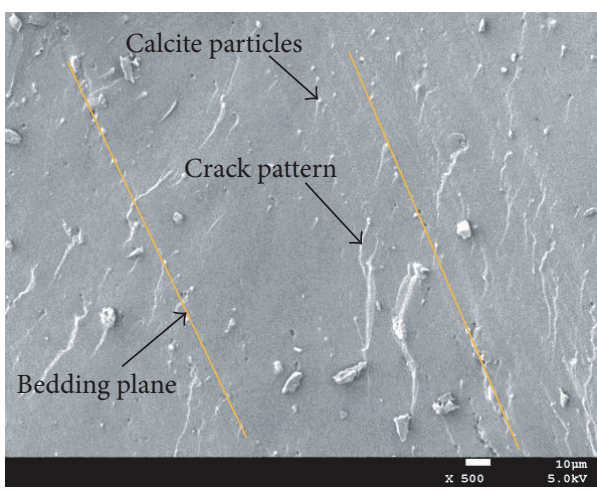

(a)

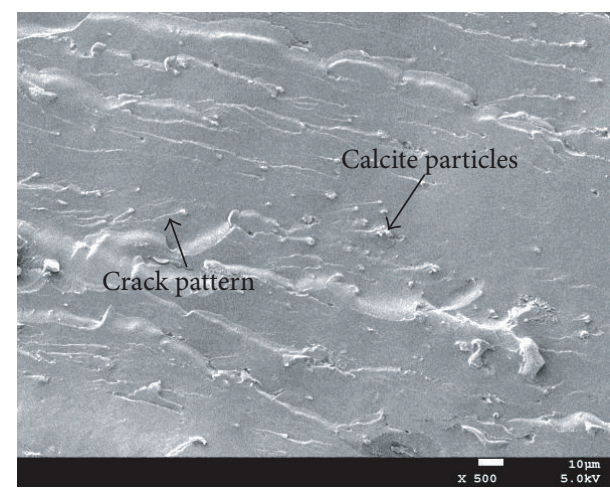

(b)

FIGURE 2: SEM images of the failure surface $(\times 500)$ : (a) the failure surface which is vertical to the bedding planes, (b) the failure surface which is parallel to the bedding planes.

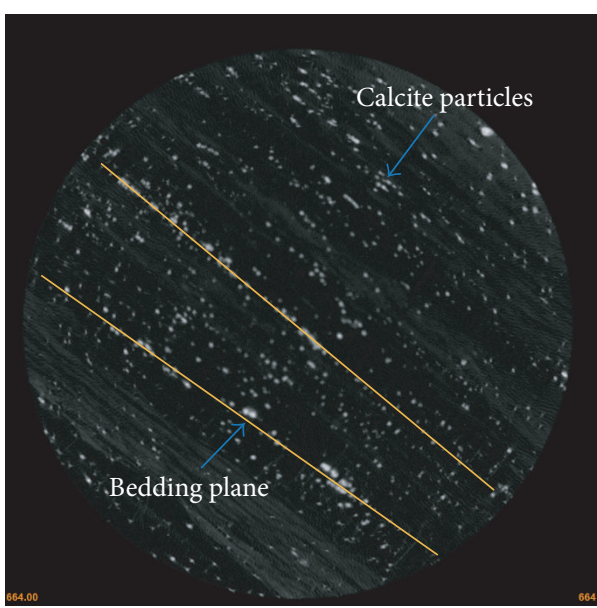

(a)

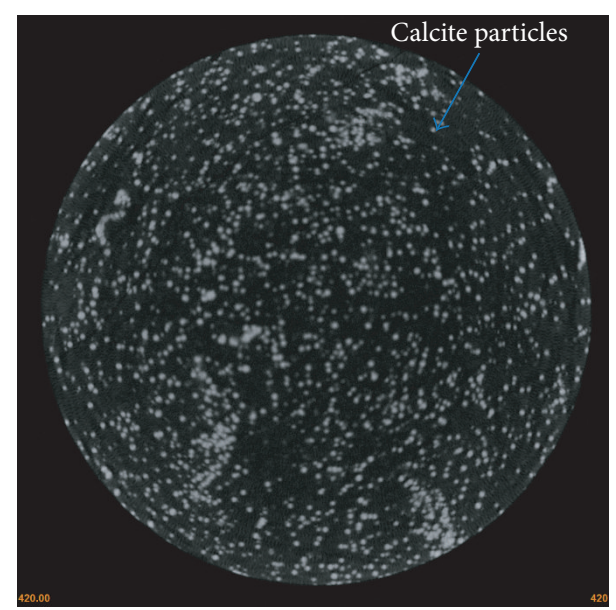

(b)

FIgURE 3: Typical cross-sectional ICT images of specimens: (a) scan of parallel specimen $(\Phi 50 \mathrm{~mm} \times H 100 \mathrm{~mm})$, (b) scan of perpendicular specimen $(\Phi 50 \mathrm{~mm} \times H 100 \mathrm{~mm})$.

represented as parallel lines are located in the calcite particle concentration areas.

From above analysis, one can conclude that the mechanism of crack evolution in Tashan coal mass should be as follows: microcracks initiate at stress concentration region close to calcite particles firstly; then these cracks begin to propagate driven by accumulated deformation energy and, eventually, they connect with each other; in the end, when the energy released by crack expanding decreases to a balanced state, crack propagation stops and a macroscopic crack is formed.

Comparing the crack patterns in Figures 2(a) and 2(b) obtained from the same magnification and equal scanning area, it is clear that there are more complex crack patterns on failure surface along bedding plane than perpendicular to it. The microcracks have been freely developed along the bedding planes but not freely extended in the direction vertical to it, which can be recognized from the phenomenon that the crack patterns in Figure 2(a) deflected along the bedding planes. The bedding structures have an obvious effect on the growth direction of microcracks; consequently, the occurrence of macroscopic cracks is influenced. In brief, calcite particles primarily distribute alone the bedding structure planes in coal, which significantly affect the evolution process of cracks in different directions. Accordingly, the macroscopic mechanical properties of coal differ considerably depending on the direction of bedding structure.

3.2. Uniaxial Compression Tests. The basic geometrical parameters and main results of the tested coal specimens are summarized in Table 1 . All specimens are grouped within two types according to the direction of bedding structure and sample axis, and the bedding plane distributed in each sample at the same group is kept as much similar as possible. The physical dimensions of all specimens listed in Table 1 meet the requirements in ASTM standard D4543-08.

3.2.1. Strength Analyses. As shown in Table 1, the average peak stress of parallel specimens is 6.95 MPa. But the average 


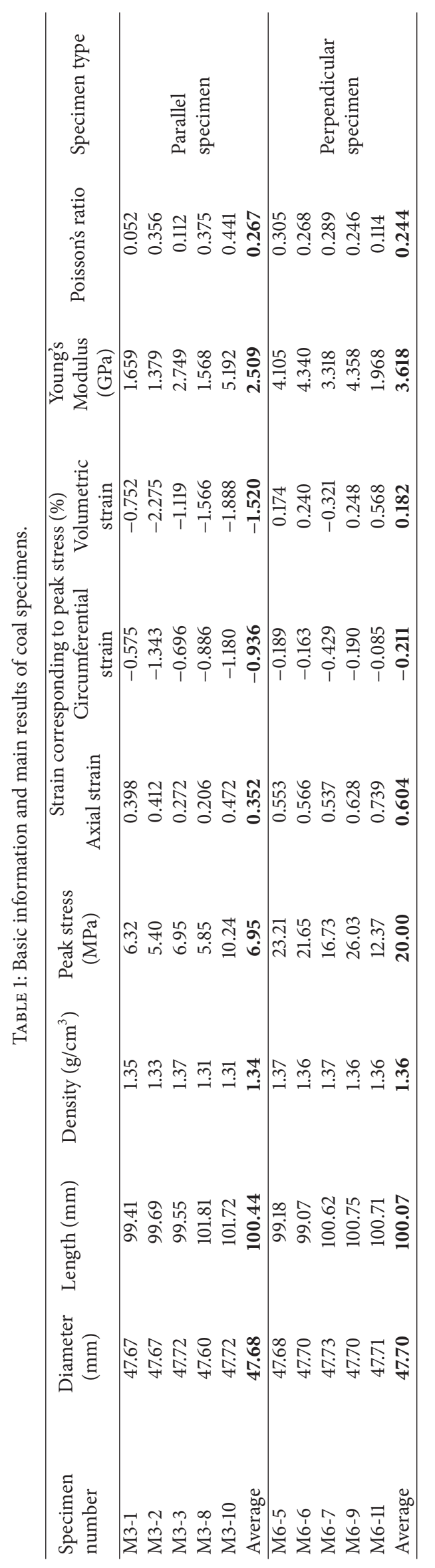




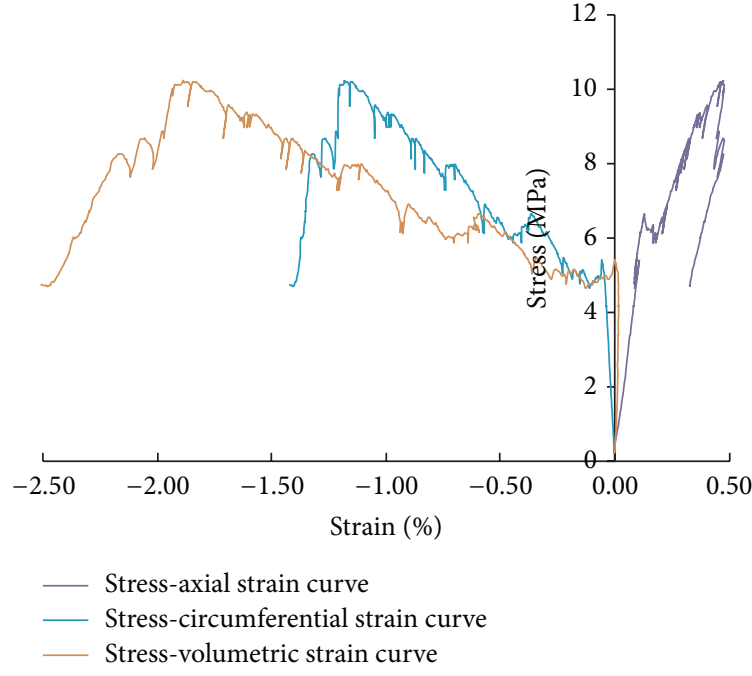

(a) M3-10

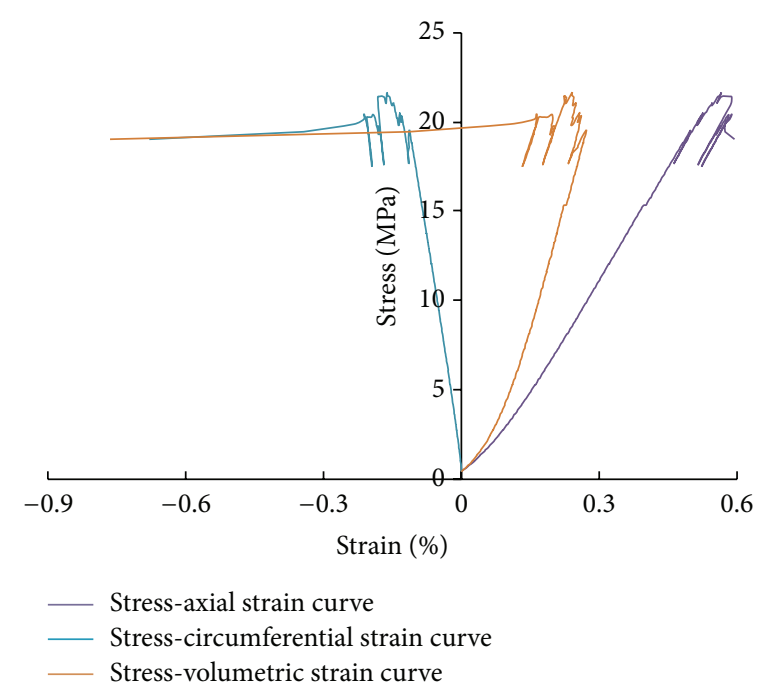

(b) M6-6

FIGURE 4: Complete stress-strain curves of typical specimens (M3-10 parallel specimen and M6-6 perpendicular specimen).

peak stress of perpendicular specimens is $20.00 \mathrm{MPa}$, which is 2.88 times the average amount of parallel specimens. As the peak stress equals the uniaxial strength of specimen in uniaxial compression tests, the strength of coal in the direction perpendicular to the bedding planes is much higher than the strength of coal in the direction parallel to the bedding planes. As explored previously, the calcite particles in coal mainly distribute near or on the bedding planes and they do have an effect on the crack growth process. It is easier for the cracks to fully develop along the bedding planes than to pass through the bedded layers between them because the latter situation requires more energy input. One can conclude that the micromechanism for strength anisotropy of coal samples is the differently distributed mineral components.

The bedding planes of coal can be considered as natural weak planes controlling the coal strength. The axial stress for parallel specimen induces tensile stress on the bedding planes, which can strongly promote the initiation, propagation, and connection of cracks, and eventually leads to failure of coal specimens. However, the axial stress for perpendicular specimen introduces compression stress on the bedding planes. It promotes closure of the cracks and makes the perpendicular specimen have a higher carrying capacity at the same axial loading condition than the parallel ones.

Combining above analyses, macroscopic cracks usually appear in the bedding planes of parallel specimen at a lower axial stress level than the perpendicular one. As a result, the average peak strength of parallel specimens is significantly lower than the perpendicular ones.

3.2.2. Deformation and Failure Process Analyses. The deformation and failure characteristics of each coal specimen, which are closely related to its strength, should be studied. The deformation testing results are listed in Table 1, and the complete stress-strain curves as well as the failure images of typical parallel specimen (M3-10) and perpendicular specimen (M6-6) are shown in Figures 4 and 5.

According to the data in Table 1, the average amount of axial strain, circumferential strain, and volumetric strain at peak stress of parallel specimens is $0.352 \%,-0.936 \%$, and $-1.520 \%$, respectively. And the average amount of axial strain, circumferential strain, and volumetric strain of perpendicular specimens at peak stress is $0.604 \%,-0.211 \%$, and $0.182 \%$, respectively. The average Young's modulus and Poisson's ratio of parallel specimens are $2.509 \mathrm{GPa}$ and 0.267 , respectively, and the corresponding average amount of perpendicular specimen is $3.618 \mathrm{GPa}$ and 0.244 , respectively.

The above testing results show that the average axial deformation of parallel specimens is $58.28 \%$ of the amount of perpendicular ones, while the average hoop deformation of parallel specimens is nearly 4.44 times the amount of perpendicular ones because cracks along bedding planes of parallel specimens open significantly under uniaxial loading conditions. The complete stress-strain curves of typical specimens shown in Figure 4 also show that the parallel specimen has an apparent larger hoop deformation than the perpendicular one before the appearance of peak strength. As is shown in Figure 5, the opening degree of macroscopic cracks of typical parallel specimen M3-10 is obviously larger than the degree of perpendicular one.

The volumetric strain of parallel specimen at peak stress is less than zero which indicates that the volume of specimen increases comparing with its initial value, while the volumetric strain of perpendicular specimen at peak stress is larger than zero reflecting a decrease in its volume. There is a significant dilatancy of parallel specimen before reaching the peak stress, which differs from the perpendicular specimens as the volumetric dilatancy phenomenon appears in the postpeak sections with the appearance of macroscopic cracks.

The value of Young's modulus for parallel specimens is generally lower than the value of perpendicular specimens, 


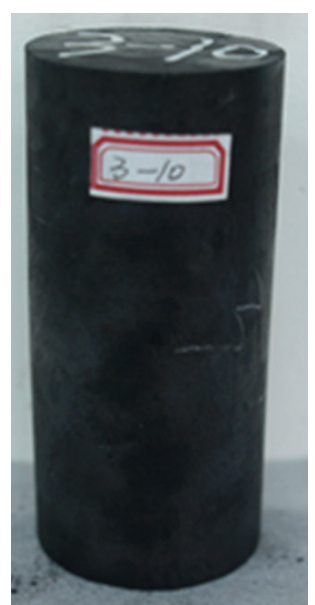

Before test (M3-10)

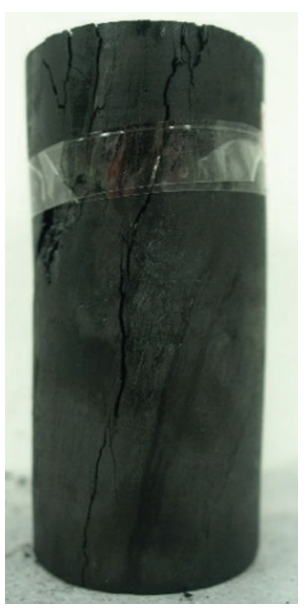

After test (M3-10)

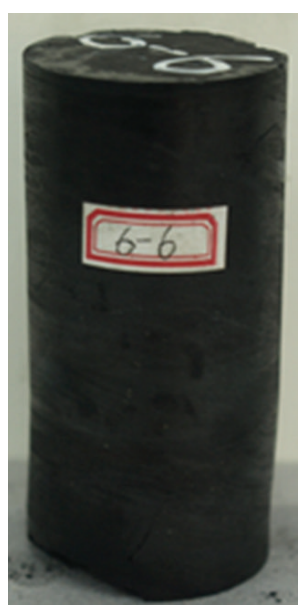

Before test (M6-6)

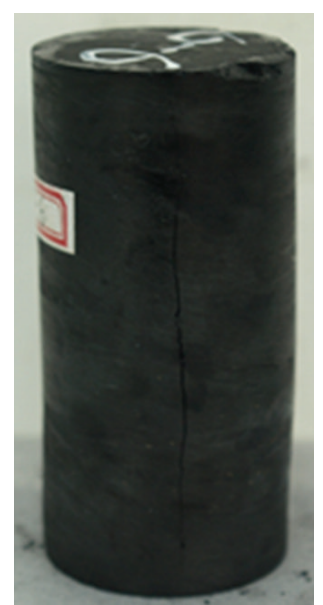

After test (M6-6)

FIGURE 5: Images of typical specimens before and after uniaxial compression tests (M3-10 parallel specimen and M6-6 perpendicular specimen).

which indicates that parallel specimens can achieve the targeted value of axial deformation at a lower axial stress level comparing with the perpendicular specimens. Obviously, there is a difference in axial deforming capacity between parallel specimens and perpendicular specimens due to different distribution of bedding structure within coal samples.

According to Zhao and Cai [16], the deformation characteristics of each coal specimen are closely associated with its failure process. For parallel specimens, microcracks distributing along the bedding planes initiate, grow, and connect with each other during the uniaxial loading process. They gradually open in the direction perpendicular to the bedding planes, which causes a significant hoop deformation and dilatancy before the appearance of peak stress. Along with the gradual failure process of coal specimens, the carrying capacity of parallel specimens goes up and down in a short time as a result of crack rapid propagation shown indirectly in Figure 4(a). Finally the macroscopic cracks form and distribute on the parallel bedding planes which marks the end of failure process of coal specimens shown in Figure 5. But, when it comes to perpendicular specimens, it is difficult for the microcracks to propagate along the bedding planes since they are compressed tightly under the uniaxial loading. Along with the increase of axial stress, microcracks initiate and grow in the direction vertical to the bedding plane and then connect to be macroscopic cracks along the direction of axial stress. In this process, because the opening range of cracks distributing along the direction perpendicular to the bedding planes is quite small as a result of the resistance of cracks in breaking through the bedded layers, no significant hoop deformation exists for perpendicular specimen before the appearance of peak stress. These specimens will not have a dilatancy until the macroscopic cracks finally appear and quickly open up under the axial compression loading.

In conclusion, the bedding structures of coal have an appreciable impact on the deformation characters and failure process of coal which are closely associated with the strength of coal.

\section{Conclusions}

To study the effect of bedding structures on the mechanical behavior of bituminous coal taken from Shanxi Province, China, a series of uniaxial compression tests and mesoscopic tests have been conducted. And a number of significant results are obtained. Firstly, the mineral components of coal, calcite particles, mainly concentrate on the bedding structures under mesoscopic scale, and they have significant influence on the growth of cracks and the macroscopic mechanical properties of coal. Secondly, the bedding structures of coal can be considered as natural weak planes controlling the coal strength; the average peak stress of perpendicular specimens is $20.00 \mathrm{MPa}$ which is 2.88 times the average amount of parallel specimens. Thirdly, the bedding structures have an appreciable impact on the deformation and failure characteristic of coal. The average hoop deformation of parallel specimens at the peak stress is nearly 4.44 times the amount of perpendicular ones because cracks along bedding planes of parallel specimens open significantly under uniaxial loading conditions.

\section{Conflict of Interests}

The authors declare that there is no conflict of interests regarding the publication of this paper.

\section{Acknowledgments}

This research was funded by the State Key Basic Research Program of China (no. 2011CB201201 and 2010CB226802) and the National Natural Science Foundation of China (no. 51204113, 51134018, and 50674092).

\section{References}

[1] L. Qi and X. Chen, "Analysis on the influence of coal strength to risk of outburst," Procedia Engineering, vol. 26, pp. 602-607, 2011. 
[2] M. L. Jeremic, "Coal strengths in the Rocky Mountains," World Coal, vol. 6, no. 9, pp. 40-43, 1980.

[3] W. A. Hustrulid, "A review of coal pillar strength formulas," Rock Mechanics Felsmechanik Mécanique des Roches, vol. 8, no. 2, pp. $115-145,1976$.

[4] Z. T. Bieniawski, "The effect of specimen size on compressive strength of coal," International Journal of Rock Mechanics and Mining Sciences and, vol. 5, no. 4, pp. 325-335, 1968.

[5] Z. P. Bažant, "Size effect on structural strength: a review," Archive of Applied Mechanics, vol. 69, no. 9-10, pp. 703-725, 1999.

[6] B. Huang and J. Liu, "The effect of loading rate on the behavior of samples composed of coal and rock," International Journal of Rock Mechanics and Mining Sciences, vol. 61, pp. 23-30, 2013.

[7] C. Wang, M. He, X. Zhang, Z. Liu, and T. Zhao, “Temperature influence on macro-mechanics parameter of intact coal sample containing original gas from Baijiao Coal Mine in China," International Journal of Mining Science and Technology, vol. 23, no. 4, pp. 597-602, 2013.

[8] R. D. West, G. Markevicius, V. M. Malhotra, and S. Hofer, "Variations in the mechanical behavior of Illinois bituminous coals," Fuel, vol. 98, pp. 213-217, 2012.

[9] N. I. Aziz and W. Ming-Li, "The effect of sorbed gas on the strength of coal-an experimental study," Geotechnical and Geological Engineering, vol. 17, no. 3-4, pp. 387-402, 1999.

[10] Y. Ates and K. Barron, "The effect of gas sorption on the strength of coal," Mining Science and Technology, vol. 6, no. 3, pp. 291300, 1988.

[11] J. Pan, Z. Meng, Q. Hou, Y. Ju, and Y. Cao, "Coal strength and young's modulus related to coal rank, compressional velocity and maceral composition," Journal of Structural Geology, vol. 54, pp. 129-135, 2013.

[12] H. Sato, J. W. Patrick, and A. Walker, "Effect of coal properties and porous structure on tensile strength of metallurgical coke," Fuel, vol. 77, no. 11, pp. 1203-1208, 1998.

[13] P. G. Ranjith and M. S. A. Perera, "Effects of cleat performance on strength reduction of coal in $\mathrm{CO}_{2}$ sequestration," Energy, vol. 45, no. 1, pp. 1069-1075, 2012.

[14] C. Li, J. Liu, C. Wang, J. Li, and H. Zhang, "Spectrum characteristics analysis of microseismic signals transmitting between coal bedding," Safety Science, vol. 50, no. 4, pp. 761-767, 2012.

[15] D. W. Hobbs, "The strength of rectangular blocks of barnsley hard coal crushed parallel to the bedding planes," Proceedings of the Physical Society, vol. 80, no. 2, article 317, pp. 497-507, 1962.

[16] X. G. Zhao and M. Cai, "A mobilized dilation angle model for rocks," International Journal of Rock Mechanics and Mining Sciences, vol. 47, no. 3, pp. 368-384, 2010. 

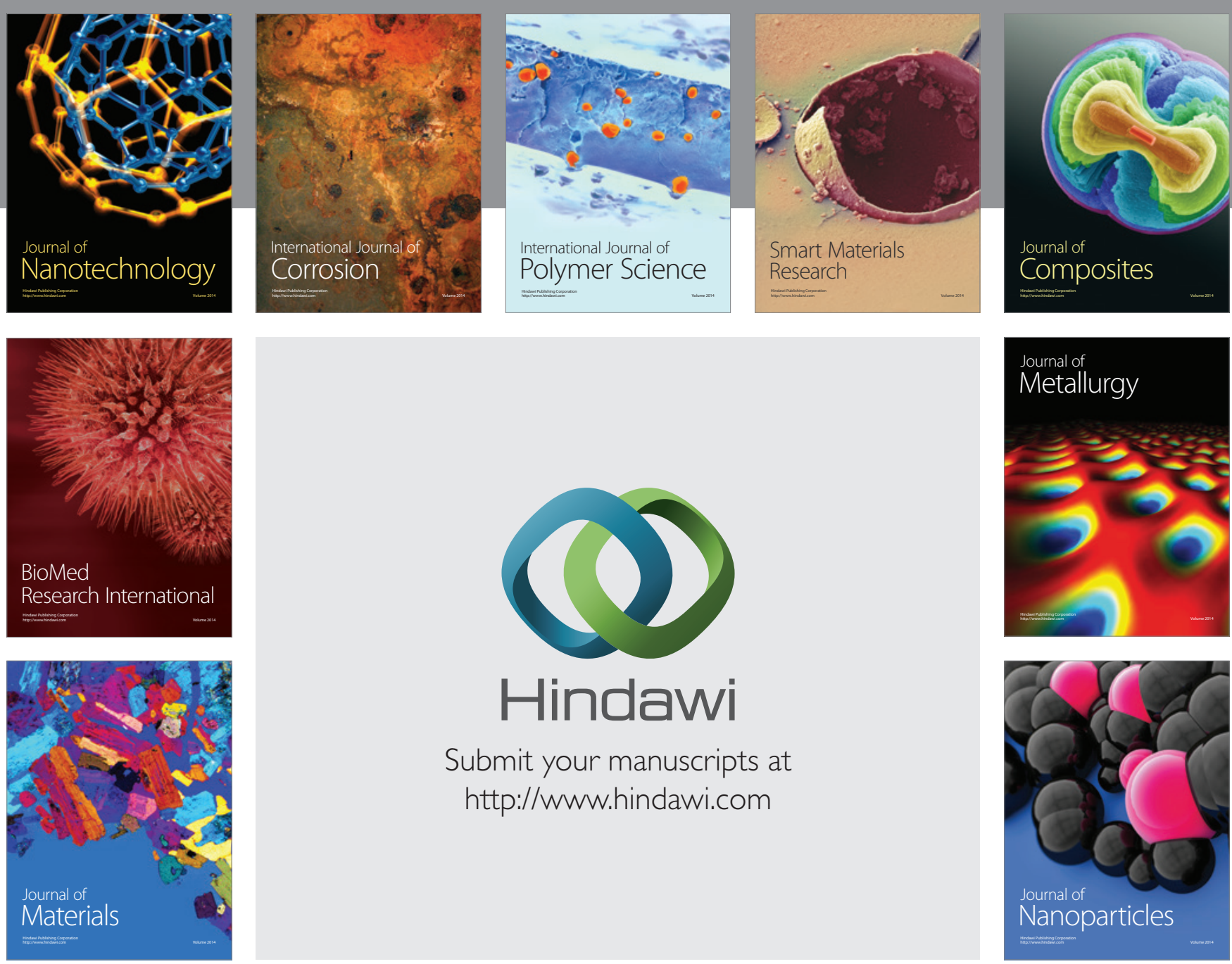

Submit your manuscripts at http://www.hindawi.com
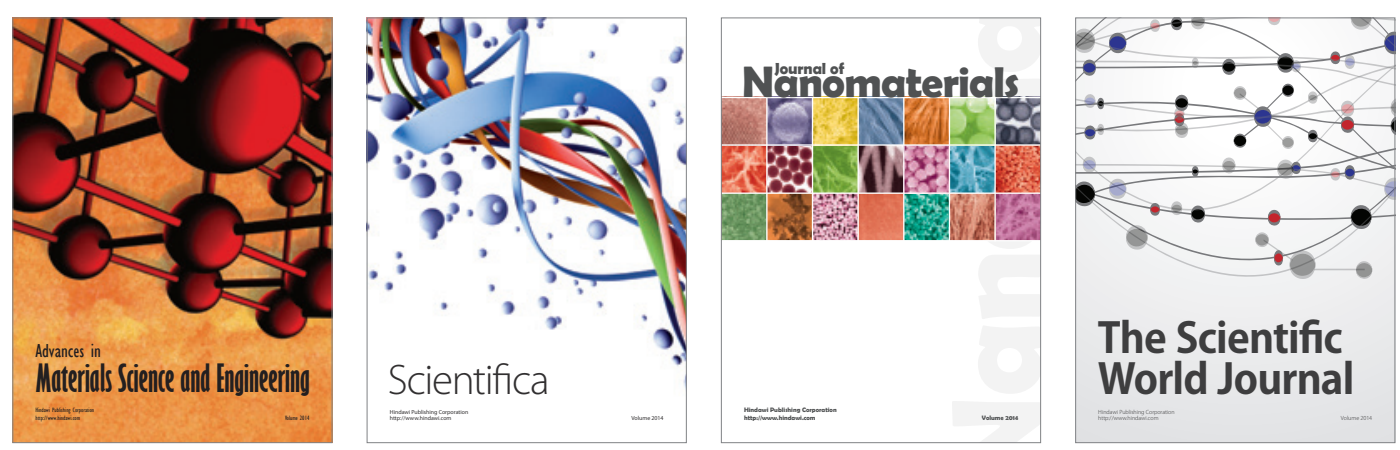

\section{The Scientific World Journal}
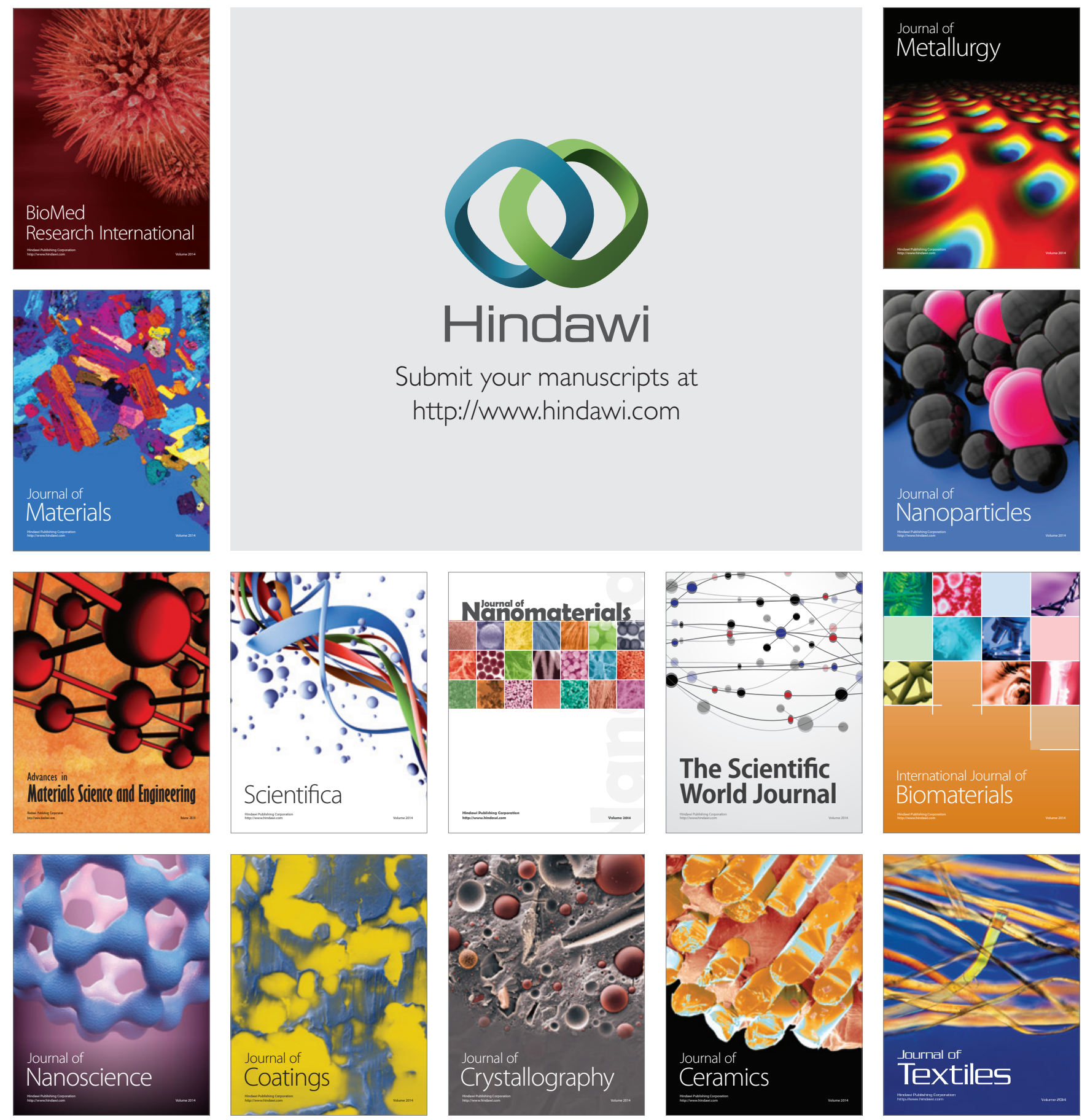